\title{
P Wave Morphology of an Arrhythmogenic Focus in Patients With Atrial Fibrillation Originating From a Pulmonary Vein or the Superior Vena Cava
}

\author{
Kimie Ohkubo, MD; Ichiro Watanabe, MD; Takeshi Yamada, MD; Yasuo Okumura, MD; \\ Kenichi Hashimoto, MD; Sonoko Ashino, MD; Masayoshi Kofune, MD; \\ Tatsuya Kofune, MD; Atsushi Shindo, MD; Hidezou Sugimura, MD; \\ Toshiko Nakai, MD; Satoshi Kunimoto, MD; Atsushi Hirayama, MD
}

\begin{abstract}
Background It was hypothesized that atrial premature contractions (APCs) originating in the pulmonary veins (PVs) or superior vena cava (SVC) can be localized by evaluating characteristics of the $\mathrm{P}$ wave.

Methods and Results Thirty-eight patients with paroxysmal atrial fibrillation were studied. P wave polarity and morphology of the ECGs during pacing from PVs were analyzed and compared to those of APCs originating from PVs. The P wave angle and notch in lead II during pacing from the right superior (RS) PV and SVC was compared to those of spontaneous APCs originating from those veins. A positive P wave in lead I was helpful in predicting right $\mathrm{PV}$ origin. A positive $\mathrm{P}$ wave in lead II distinguished superior $\mathrm{PV}$ origin. A notched $\mathrm{P}$ wave was helpful in predicting left PV origin. P wave polarity in lead II was positive during RSPV and SVC pacing. P waves in lead II during RSPV pacing had notching in $80 \%$, but all $\mathrm{P}$ waves were smooth during SVC pacing. A P wave angle of $>40^{\circ}$ and notching in lead II showed RSPV origin.
\end{abstract}

Conclusions These criteria are helpful in selecting which of the 4 PVs should be isolated when APCs cannot be recorded after transseptal puncture. (Circ J 2008; 72: 1650-1657)

Key Words: P wave morphology; Paroxysmal atrial fibrillation; Surface ECG

$\mathbf{P}$ aroxysmal atrial fibrillation (AF) can be triggered by atrial premature contractions (APCs) originating from a focal area. Most APCs originate from the orifice of a pulmonary vein $(\mathrm{PV})$ or from the myocardial sleeve inside a PV!-6 PV isolation by radiofrequency (RF) catheter ablation has been shown to effectively eliminate this type of AF!-6 In addition, several studies have revealed the importance of non-PV APCs in triggering AF ? $^{-9}$ Previous studies showed that pacemapping from each of the PVs and superior vena cava (SVC) reveals unique surface ECG characteristics and spontaneous APC from the PVs and SVC! ${ }^{10-14}$ It follows that the surface ECG characteristics of spontaneous APCs might help to localize the PV and/or non-PV origin of these triggers and guide ablation when APCs triggering AF do not occur spontaneously or cannot be induced during endocavitary exploration. However, no previous reports compared morphology of the paced $\mathrm{P}$ wave and spontaneous P wave from the PVs and SVC by simple algorithm.

The purpose of this 2-part study was to systematically apply simple ECG criteria, which was developed from pacemapping from the PVs and SVC based on previous studies,

(Received January 30, 2008; revised manuscript received May 28, 2008; accepted June 10, 2008; released online September 1, 2008)

Division of Cardiology, Department of Cardiovascular Disease, Nihon

University School of Medicine, Tokyo, Japan

Mailing address: Ichiro Watanabe, MD, Division of Cardiology, Department of Medicine, Nihon University School of Medicine, 30-1 Oyaguchi-Kamimachi, Itabashi-ku, Tokyo 173-8610, Japan. E-mail: iwatanab@med.nihon-u.ac.jp

All rights are reserved to the Japanese Circulation Society. For permissions, please e-mail: cj@j-circ.or.jp to spontaneously occurring APCs originating from the PVs and the SVC because the SVC and right superior (RS) PV are anatomically close, and thus, $\mathrm{P}$ wave morphology of the ectopic beats originating from the SVC or RSPV might be similar. We hypothesized that criteria developed from PV and SVC pacemapping would allow discrimination of right from left PV, superior from inferior PV origin and RSPV from SVC origin of APCs.

\section{Methods \\ Study la \\ Patient Population Fifteen patients (11 men and 4} women; mean age, $46 \pm 12$ years) undergoing RF catheter ablation by transseptal approach for a left-sided accessory pathway $(n=14)$ or left-sided atrial tachycardia $(n=1)$ were included in this study. Informed consent was obtained from all patients before the procedure (study $1 \mathrm{a}, 1 \mathrm{~b}$ and 2) according to the protocol approved by the Nihon University Itabashi Hospital's Human Research Committee.

Study Protocol After successful ablation of the accessory pathway or atrial tachycardia, a 7F, 4-mm-tip quadripolar steerable ablation catheter (EP Technologies, Sunnyvale, CA, USA) was introduced through a long sheath into the proximal portion (within $2 \mathrm{~cm}$ from the PV orifice) of each (RS, right inferior (RI), left superior (LS) and left inferior (LI)) PV, close to the ostium. The position of the ablation catheter within each PV was verified in all patients by its fluoroscopic appearance outside the cardiac silhouette and by PV angiography. Patients with common left PV ostium and with right middle PV were excluded from the study. Of the $60 \mathrm{PVs}$ in the 15 patients, $60 \mathrm{PVs}(100 \%)$ were success- 


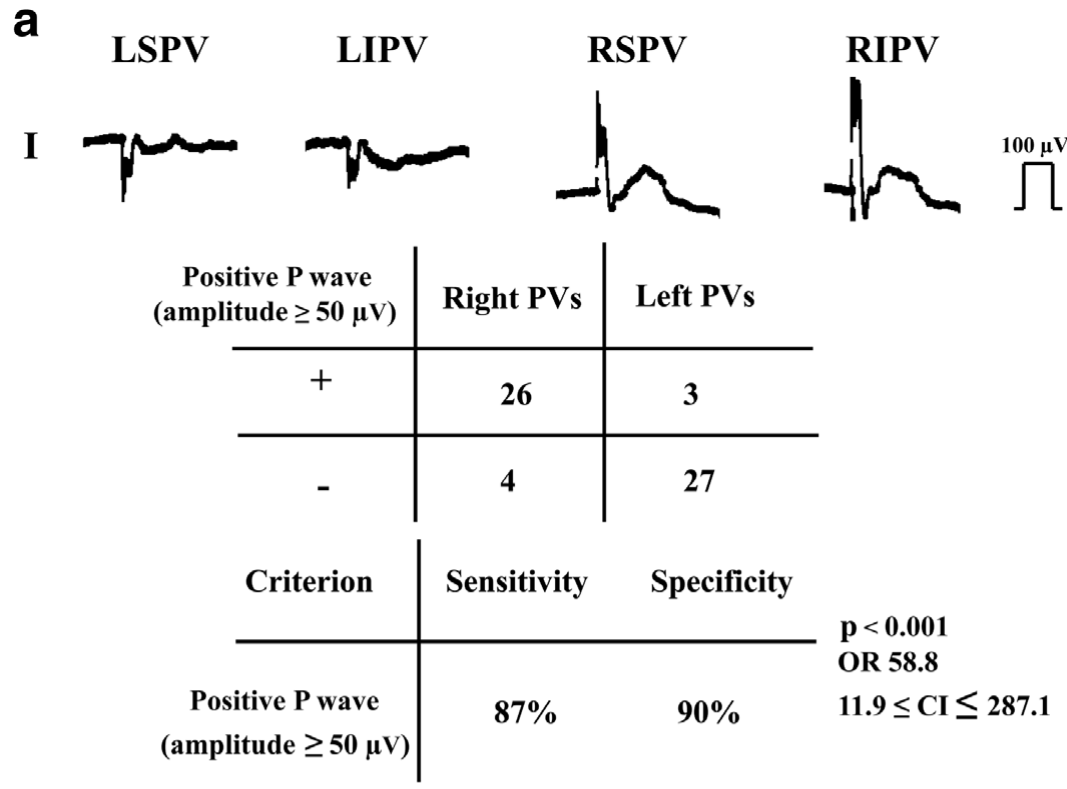

b

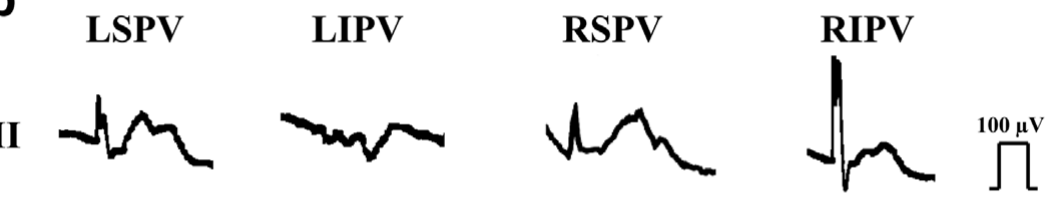

\begin{tabular}{c|c|c}
$\begin{array}{c}\text { Positive P wave } \\
\text { amplitude } \geq 100 \mu \mathrm{V})\end{array}$ & Superior PVs & Inferior PVs \\
\hline+ & 24 & 9 \\
- & 6 & 21
\end{tabular}

\begin{tabular}{c|ccc} 
Criterion & Sensitivity & Specificity & \\
\hline $\begin{array}{c}\text { Positive P wave } \\
\text { (amplitude } \geq 100 \mu \mathrm{V})\end{array}$ & $\mathbf{8 0 \%}$ & $\mathbf{7 0 \%}$ & $\begin{array}{l}\text { OR }<.33 \\
2.8 \leq \text { CI } \leq 30.6\end{array}$
\end{tabular}

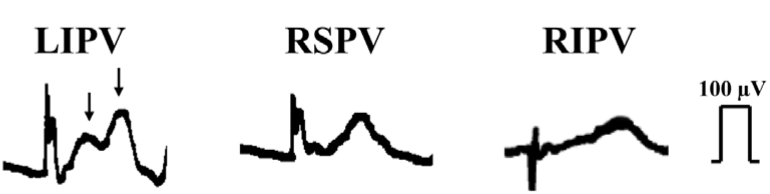

\begin{tabular}{c|c|c}
$\begin{array}{c}\text { Positive P wave } \\
\text { (bimodal peak) }\end{array}$ & Left PVs & Right PVs \\
\hline+ & 21 & 9 \\
\hline- & 9 & 20
\end{tabular}

\begin{tabular}{c|ccl} 
Criterion & Sensitivity & Specificity & $\begin{array}{l}\text { p }<0.005 \\
\text { OR 5.44 }\end{array}$ \\
& & & $1.8 \leq$ CI $\leq 16.4$ \\
$\begin{array}{c}\text { Positive P wave } \\
\text { (bimodal peak) }\end{array}$ & $70 \%$ & $69 \%$ &
\end{tabular}

Fig 1. (a) $\mathrm{P}$ wave amplitude in lead I during pacing from 4 PVs. Note that a $\mathrm{P}$ wave amplitude of $\geq 50 \mu \mathrm{V}$ differentiates the $\mathrm{P}$ wave of right $\mathrm{PV}$ origin from that of left $\mathrm{PV}$ origin. (b) $\mathrm{P}$ wave amplitude in lead II during pacing from 4 PVs. Note that the $\mathrm{P}$ wave amplitude of $\geq 100 \mu \mathrm{V}$ differentiates a $\mathrm{P}$ wave of superior $\mathrm{PV}$ origin from that of inferior PV origin. (c) $\mathrm{P}$ wave morphology in lead $\mathrm{V}_{1}$ during pacing from 4 PVs. Note that the notched $\mathrm{P}$ wave morphology with the second component larger than the first component differentiates APCs of left PV origin from those of right left pulmonary origin. PV, pulmonary vein; APC, atrial premature contraction; LSPV, left superior pulmonary vein; LIPV, left inferior pulmonary vein; RSPV, right superior pulmonary vein; RIPV, right inferior pulmonary vein; OR, odds ratio; $\mathrm{CI}$, confidence interval. 

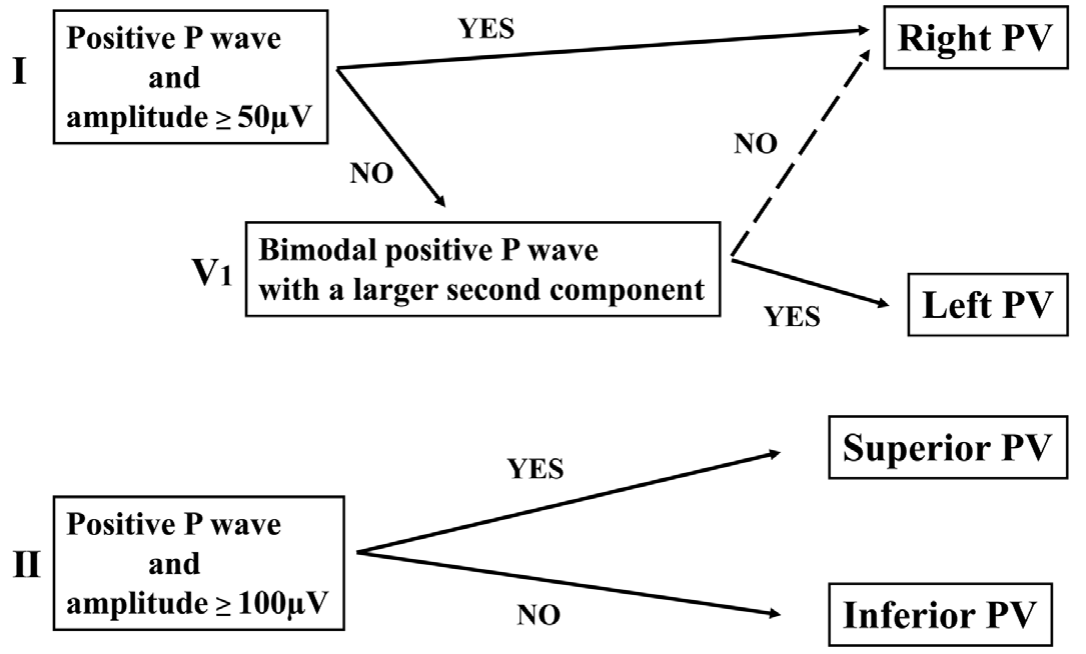

Fig 2. Algorithm for determining PV origin. A positive $\mathrm{P}$ wave in lead I greater than $50 \mu \mathrm{V}$ indicates right $\mathrm{PV}$ origin; a positive $\mathrm{P}$ wave in lead II greater than $100 \mu \mathrm{V}$ indicates a superior PV origin, and a notched shape in $\mathrm{V}_{1}$ indicates left PV origin. Abbreviation see in Fig 1.

fully cannulated. Bipolar pacing was performed at a cycle length of $600-800 \mathrm{~ms}$ with a minimum current strength of $4.4 \pm 1.0 \mathrm{~V}$ and $2 \mathrm{~ms}$ duration.

$P$ Wave Analysis $\mathrm{P}$ waves were analyzed by 2 blinded observers on 12-lead ECG's recorded at a paper speed of $50 \mathrm{~mm} / \mathrm{s}$ and amplitude of $0.5 \mathrm{mV} / \mathrm{cm}$. The $\mathrm{P}$ wave configuration was classified according to amplitude as $\geq 100 \mu \mathrm{V}$ or $<100 \mu \mathrm{V}$ in lead I (Fig 1a), as $\geq 50 \mu \mathrm{V}$ or $<50 \mu \mathrm{V}$ in lead II (Fig 1b) based on the crude method of amplitude measurement through square-counting based on a previous study 12 and notching with amplitude of the second component being larger than the first component in lead V1 (Fig 1c). Only $\mathrm{P}$ waves that were clearly visible and isolated from the preceding $\mathrm{T}$ waves were analyzed. One $\mathrm{V}_{1}$ lead ECG during RSPV pacing could not be analyzed because of the presence of a large noise.

\section{Study $1 b$}

Patient Population Twenty-five patients with paroxysmal AF (23 men and 2 women; mean age, $59 \pm 11$ years) undergoing segmental isolation of the 4 PVs by a transseptal approach were included in this study. Two long sheaths (SL1; Daig Corp, Minnetonka, MN, USA) were inserted into the left atrium via transseptal puncture under fluoroscopic guidance. A 7F Trio $^{\mathrm{TM}}$ guide sheath (Cardiac Pathways Corp, Sunnyvale, CA, USA) with 3 ports was introduced into the SL1 sheath, and 3, 2F quadripolar catheters with 5$\mathrm{mm}$ interelectrode spacing (Ensemble ${ }^{\mathrm{TM}}$, Cardiac Pathways Corp) were positioned; 1 at the LSPV, 1 at the LIPV and 1 at the RSPV. A 7F deflectable quadripolar catheter with 2-5-2mm spacing (EP Technologies) was positioned in the RIPV through another SL1 sheath. A 20-pole catheter (A 20; Cordis-Webster, Baldwin Park, CA, USA) was placed in the posteroseptal right atrium, and a decapolar catheter with an end-hole was placed in the coronary sinus (Daig Corp) before PV isolation. Patients with common left PV ostium and with a right middle PV were excluded from the study.

Study Protocol Intracardiac bipolar electrograms were displayed simultaneously with ECG leads I, II, III, V1 and $\mathrm{V}_{6}$ on a multichannel recorder (CardioLab System, Prucka Engineering Inc, Houston, TX, USA). The filter was set at $0.05-100 \mathrm{~Hz}$ for surface ECG and $30-500 \mathrm{~Hz}$ for intracardiac recordings. We first attempted to locate the spontaneous onset of APCs triggering AF in the baseline condition or during isoproterenol infusion (up to $4 \mu \mathrm{g} / \mathrm{min}$ ). We could localize the origin of APC by identifying the earliest activation within the PV before activation of the other 3 PVs, coronary sinus activation and right atrial activation. If spontaneous AF did not appear, intermittent atrial pacing (812 beats) with a cycle length of $200-300 \mathrm{~ms}$ from the high right atrium or coronary sinus was used to induce sustained AF. After the pacing-induced AF was sustained for 510 min, external cardioversion was attempted to convert AF to sinus rhythm so that we could observe the spontaneous re-initiation of AF. Then we paced the PV(s) (from which APC originated) in the same manner described in study 1a.

$P$-Wave Analysis Morphology of the APCs was analyzed by 2 blinded observers on 12-lead ECGs, recorded at a paper speed of $50 \mathrm{~mm} / \mathrm{s}$ and at an amplitude of $0.5 \mathrm{mV} / \mathrm{cm}$, and the morphologies of the paced $\mathrm{P}$ wave and APCs originating from the PV were compared. Because of the difficulty in measuring the amplitude of the $\mathrm{P}$ waves superimposed on the ST-T segment, we qualitatively measured P wave morphology as positive, biphasic and negative.

\section{Study 2}

Patient Population Thirteen patients with paroxysmal $\mathrm{AF}$ (11 men and 2 women; mean age, $52 \pm 15$ years) who were undergoing segmental isolation of 4 PVs by a transseptal approach were included in this study. After transseptal puncture, 2 SL1 sheaths (Daig Co) were inserted into the left atrium via transseptal puncture under fluoroscopic guidance.

Study Protocol A 7F, 4-mm-tip quadripolar steerable ablation catheter (EP Technologies) was introduced through the long sheath into the proximal portion (within $2 \mathrm{~cm}$ from the orifice) of the RSPV. Another 6F, 4-mm-tip quadripolar steerable catheter was placed in the SVC (within $2 \mathrm{~cm}$ from the SVC and right atrial junction). Bipolar pacing from the RSPV and SVC was performed at a cycle length of 600$800 \mathrm{~ms}$ with a minimum current strength of $3.0 \pm 1.0 \mathrm{~V}$ and $2.3 \pm 0.9 \mathrm{~V}$, respectively, and $2 \mathrm{~ms}$ duration before PV isolation. We confirmed that pacing from SVC did not directly capture RSPV and vice versa by using an activation sequence; that is, the proximal to distal activation sequence of the SVC and RSPV during RSPV and SVC pacing.

$P$ Wave Analysis Morphology of the paced $\mathrm{P}$ wave was analyzed by 2 blinded observers on 12-lead ECG's, recorded at a paper speed of $50 \mathrm{~mm} / \mathrm{s}$ and at an amplitude of 
a APC from RSPV

\section{Surface ECG}

$55 \mathrm{y} / \mathrm{o}, \mathrm{M}$

(1) lead I

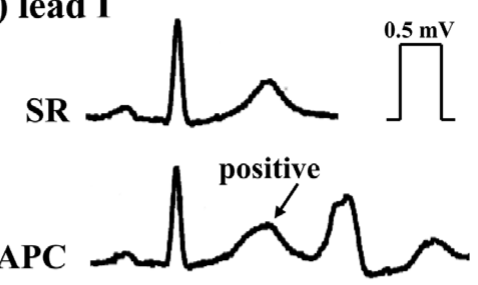

(2) lead II

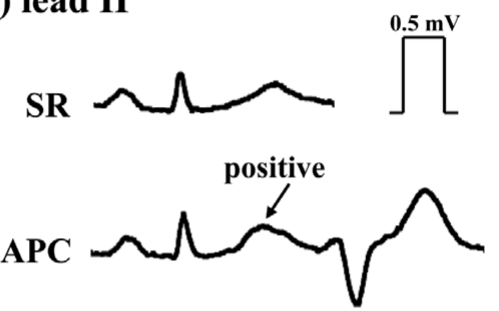

b APC from LSPV

\section{Surface ECG}

$62 \mathrm{y} / \mathrm{o}, \mathrm{F}$

(1) lead I

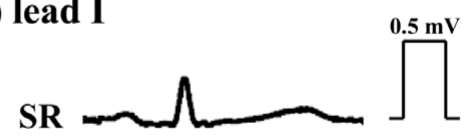

APC

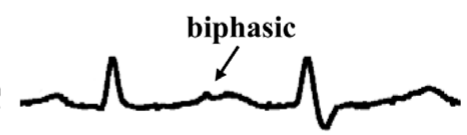

(2) lead II
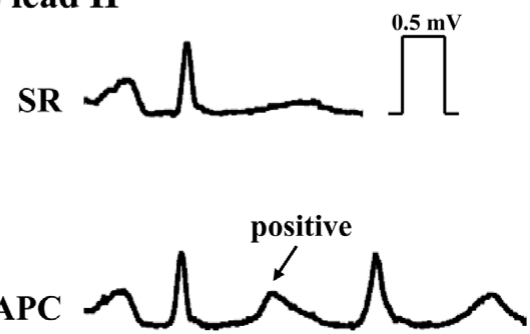

\section{APC from RIPV}

$55 \mathrm{y} / \mathrm{o}, \mathrm{M}$

Surface ECG

(1) lead I

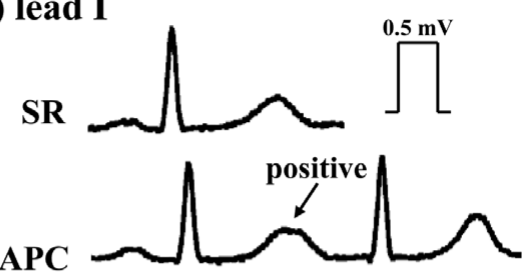

(2) lead II

SR

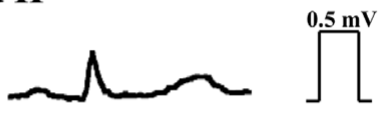

APC

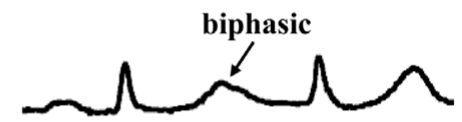

\section{APC from LIPV}

\section{Surface ECG}

\section{$60 \mathrm{y} / \mathrm{o}, \mathrm{M}$}

(1) lead I

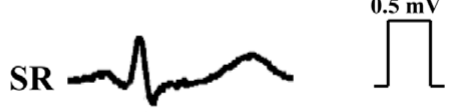

APC<smiles>CCCCCCCCCCCCC(C)(C)C</smiles>

(2) lead II

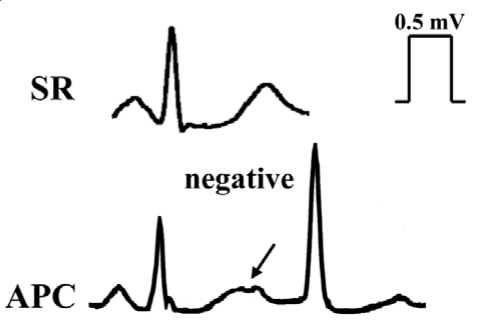

Fig 3. (a) Surface ECG of spontaneous APCs originating from RSPV and RIPV. Left-hand panel: ECG leads I and II show a spontaneous APC originating from RSPV. Right-hand panel: ECG leads I and II show a spontaneous APC originating from RIPV. The P wave was positive in lead I for the APC arising from the RSPV and RIPV. The P wave was positive in lead II for the APC arising from the RSPV, but it showed a low-amplitude, biphasic pattern for the APC arising from the RIPV. (b) Surface ECG of spontaneous APCs originating from LSPV and LIPV. Left-hand panel: ECG leads I and II show a spontaneous APC originating from LSPV. Right-hand panel: ECG leads I and II show a spontaneous APC originating from LIPV. The P wave was flat or negative in lead I for the APC arising from the LSPV and LIPV. The P wave was positive in lead II for the APC arising from the LSPV, but it showed a negative pattern for the APC arising from the LIPV. ECG, electrocardiogram; SR, sinus rhythm. Other abbreviations see in Fig 1.

$0.5 \mathrm{mV} / \mathrm{cm}$, by measuring the angle of the $\mathrm{P}$ waves manually using a protractor. The morphologies of the APCs originating from the RSPV and SVC were compared qualitatively.

\section{Statistics}

The values are expressed as the mean $\pm \mathrm{SD}$. The differ- ences in continuous variables were analyzed by the unpaired Student's t-test, and the differences in the categorical variables were analyzed by the chi-square test. StatView 5.0 software (SAS Institute) was used for data analysis. Confidence intervals of the odds ratio and the receiver-operating characteristic (ROC) curve of the $\mathrm{P}$ wave angle was calcu- 
RSPV

$55 \mathrm{y} / \mathbf{0}, \mathrm{M}$

lead II

SR

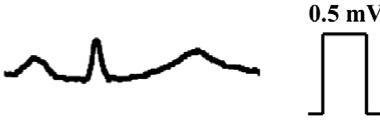

APC Positive, notch (+)

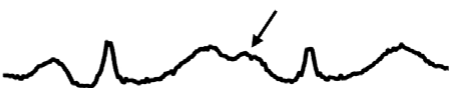

Angle

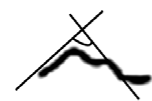

3. ECG (Pacing)
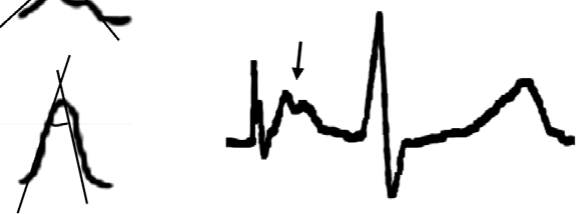

SVC

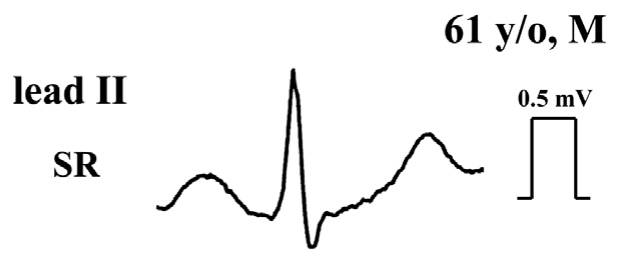

APC Positive, notch (-)

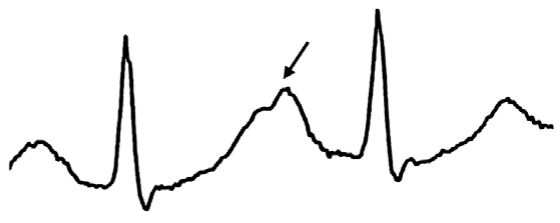

3. ECG (Pacing)

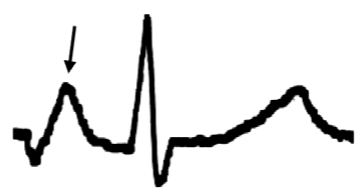

Fig 4. Comparison of the $\mathrm{P}$ wave morphology in lead II during pacing from RSPV and SVC and atrial premature contraction originating from RSPV and SVC. Note that notching of the $\mathrm{P}$ wave and $\mathrm{P}$ wave angle $\left(>40^{\circ}\right)$ differentiate APCs of RSPV origin from those of SVC origin. SVC, superior vena cava. Other abbreviations see in Fig 1.

Table 1 Evaluation of Surface ECG Criteria

\begin{tabular}{|c|c|c|c|c|c|c|c|}
\hline & $\begin{array}{c}R S P V \\
(n=15)\end{array}$ & $\begin{array}{l}R I P V \\
(n=2)\end{array}$ & $\begin{array}{l}L S P V \\
(n=8)\end{array}$ & $\begin{array}{l}L I P V \\
(n=5)\end{array}$ & $\begin{array}{c}S V C \\
(n=1)\end{array}$ & $\begin{array}{c}\text { Sensitivity } \\
(\%)\end{array}$ & $\begin{array}{c}\text { Specificity } \\
(\%)\end{array}$ \\
\hline \multicolumn{8}{|l|}{ Lead I } \\
\hline Positive & 13 & 2 & 1 & 0 & 1 & & \\
\hline Biphasic & 1 & 0 & 4 & 2 & 0 & & \\
\hline Negative & 1 & 0 & 3 & 3 & 0 & & \\
\hline \multicolumn{8}{|l|}{ Lead II } \\
\hline Positive & 13 & 0 & 6 & 1 & 1 & & \\
\hline Biphasic & 1 & 2 & 2 & 2 & 0 & & \\
\hline Negative & 1 & 0 & 0 & 2 & 0 & & \\
\hline \multicolumn{8}{|l|}{ Criteria } \\
\hline$R P V s$ vs $L P V s^{*}$ (positive $P$ wave in lead I) & & & & & & 89 & 92 \\
\hline SPVs vs IPVs** (positive P wave in lead II) & & & & & & 83 & 86 \\
\hline
\end{tabular}

RSPV, right superior pulmonary vein; RIPV, right inferior pulmonary vein; LSPV, left superior pulmonary vein; LIPV, left inferior pulmonary vein; SVC, superior vena cava.

${ }^{*} p<0.001,{ }^{* *} p<0.001$.

lated using StatFlex software. A p value of less than 0.05 was considered statistically significant.

\section{Results}

\section{Study 1 a}

Amplitude of Paced P Waves Significant differences in the amplitude of paced $\mathrm{P}$ waves were observed in leads I and II. In lead I, amplitudes of $\mathrm{P}$ waves produced by right PV pacing were significantly higher $(\geq 50 \mu \mathrm{V})$ than amplitudes of $\mathrm{P}$ waves produced by left $\mathrm{PV}$ pacing $(\mathrm{p}<0.001$, Fig 1a). In lead II, pacing from the superior PVs produced $P$ waves with significantly higher amplitudes $(\geq 100 \mu \mathrm{V})$ than those of $\mathrm{P}$ waves produced by pacing from the inferior $\mathrm{PVs}$ $(\mathrm{p}<0.001$, Fig 1b).

Morphology of Paced P Waves A significant difference in the morphology of paced $\mathrm{P}$ waves was observed in lead $\mathrm{V}_{1}$. Left PV pacing produced positive bimodal $\mathrm{P}$ waves with the second component larger than the first component, whereas right PV pacing produced positive unimodal or positive bimodal $\mathrm{P}$ waves with the first component larger than the second component ( $\mathrm{p}<0.005$, Fig 1c).

Development of an Algorithm To predict the PV pacing site origin from the analysis of the morphologic features of $\mathrm{P}$ waves during selective PV pacing, we developed an algorithm to predict the origin of the pacing site in the $\mathrm{PV}$. The combination of a P wave amplitude of $<50 \mu \mathrm{V}$ in lead I and a positive bimodal $\mathrm{P}$ wave with a larger second component in lead $V_{1}$ is taken to indicate a left-side PV origin; otherwise, the $\mathrm{P}$ wave is regarded to have come from a rightsided PV origin. A positive $\mathrm{P}$ wave amplitude in lead II of $\geq 100 \mu \mathrm{V}$ was selected to differentiate the superior PVs 
Table 2 P Wave Morphology and P Wave Angle in Lead II During RSPV and SVC Pacing

\begin{tabular}{|c|c|c|c|c|c|c|}
\hline \multirow{2}{*}{ Case } & \multirow{2}{*}{$\begin{array}{c}\text { Age (years old)/ } \\
\text { gender }\end{array}$} & \multicolumn{2}{|c|}{ Pacing notch } & \multicolumn{2}{|c|}{ Angle (degree) } & \multirow{2}{*}{$A P C$} \\
\hline & & $S V C$ & $R S P V$ & $S V C$ & $R S P V$ & \\
\hline 1 & $61 / M$ & $(-)$ & $(+)$ & 21 & 48 & $S V C$ \\
\hline 2 & $35 / M$ & $(-)$ & $(+)$ & 27 & 44 & \\
\hline 3 & $50 / F$ & $(+)$ & $(+)$ & 17 & 45 & \\
\hline 4 & $31 / F$ & $(-)$ & $(-)$ & 26 & 57 & $R S P V$ \\
\hline 5 & $55 / M$ & $(-)$ & $(+)$ & 21 & 28 & $S V C, R S P V$ \\
\hline 6 & $66 / F$ & $(-)$ & $(+)$ & 25 & 29 & \\
\hline 7 & $49 / F$ & $(-)$ & $(-)$ & 21 & 37 & $R S P V$ \\
\hline 8 & $69 / M$ & $(-)$ & $(+)$ & 27 & 59 & \\
\hline 9 & $74 / M$ & $(-)$ & $(+)$ & 39 & 63 & \\
\hline 10 & $46 / M$ & $(-)$ & $(-)$ & 32 & 40 & \\
\hline 11 & $46 / M$ & $(-)$ & $(+)$ & 38 & 53 & \\
\hline 12 & $27 / M$ & $(-)$ & $(+)$ & 38 & 55 & $S V C$ \\
\hline 13 & $67 / M$ & $(-)$ & $(+)$ & 47 & 55 & $R S P V$ \\
\hline
\end{tabular}

$A P C$, atrial premature contraction. Other abbreviations see in Table 1.

Table 3 Discrimination of RSPV vs SVC Pacing Site by P Wave in Lead II

\begin{tabular}{lcccc}
\hline \hline Criterion & Sensitivity (\%) & Specificity (\%) & OR & $95 \%$ CI \\
\hline Notching $(+)^{*}$ & 78 & 92 & 40.0 & $3.6 \leq C I \leq 447.1$ \\
Angle $>40^{\circ} * *$ & 78 & 92 & 40.0 & $3.6 \leq C I \leq 447.1$ \\
Notching $(+)$ and angle $>40^{\circ} * * *$ & 67 & 100 & 20.8 & $2.0 \leq C I \leq 211.8$ \\
\hline
\end{tabular}

OR, odds ratio; CI, confidence interval. Other abbreviations see in Table 1.

${ }^{*} p<0.0004, * * p<0.0004, * * * p<0.0006$

from inferior PVs (Fig 2).

Study $1 b$

Thirty-one APC foci were identified in the PVs and SVC: 15 in the RSPV (Fig 3a, Left), 2 in the RIPV (Fig 3a, Right), 8 in the LSPV (Fig 3b, Left), 5 in the LIPV (Fig 3b, Right) and 1 in the SVC (Fig 4). These APCs were located on the preceding $\mathrm{T}$ wave. The best sensitivity and specificity were achieved by combining the following criteria: (1) A positive $\mathrm{P}$ wave in lead I. This was present in $89 \%$ of APCs from right-sided PVs and the SVC, yielding a sensitivity of $89 \%$ and a specificity of $92 \%$ for distinguishing right (including SVC) from left PV origin of spontaneous APCs; (2) A positive $\mathrm{P}$ wave in lead II. This was present in $83 \%$ of APCs from superior PVs and the SVC, yielding a sensitivity of $83 \%$ and a specificity of $86 \%$ for distinguishing inferior from superior PV (including SVC) origin of spontaneous APCs (Table 1).

\section{Study 2}

Because APCs originating from the RSPV and SVC showed similar polarity, that is, positive $\mathrm{P}$ waves in leads I and II, we classified morphology of the $\mathrm{P}$ wave in lead II by notching and by the angle of the $\mathrm{P}$ wave formed by 2 lines tangential to the up-slope and down-slope of the $\mathrm{P}$ wave (Fig 4). Notching of the P wave was present in $77 \%$ during RSPV pacing and $7.6 \%$ during SVC pacing $(\mathrm{p}<0.0005)$, yielding a sensitivity of $78 \%$ and a specificity of $92 \%$ for distinguishing RSPV origin from SVC origin (Tables 2,3). The mean angle of the $\mathrm{P}$ wave in lead II was $47.2 \pm 11.2^{\circ}$ during RSPV pacing and $29.2 \pm 8.9^{\circ}$ during SVC pacing ( $\mathrm{p}<$ 0.001) (Fig 4; Tables 2,3). Because we paced RSPV and SVC at the pacing threshold output, the direct capture of SVC during RSPV pacing and vice versa were not observed. We decided on a $\mathrm{P}$ wave angle of $40^{\circ}$ as the $\mathrm{P}$ wave angle cut-off line to distinguish both SVC and RSPV by

\section{APC from SVC Surface ECG \\ $63 \mathrm{y} / \mathrm{o}, \mathrm{M}$}

(1) lead I
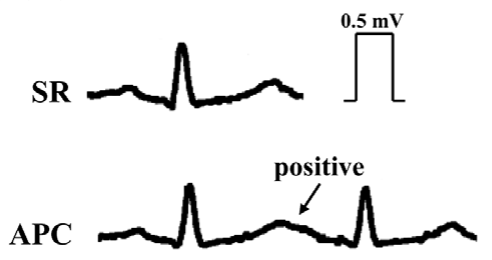

(2) lead II

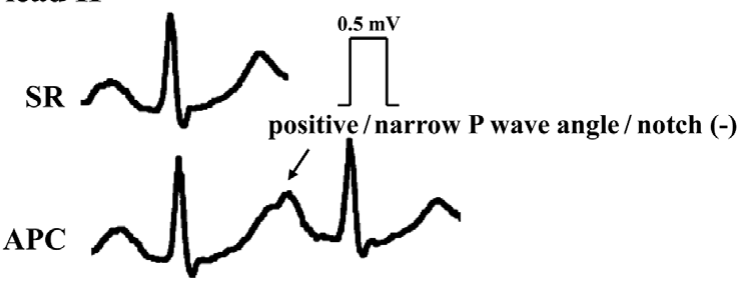

Fig 5. ECG of spontaneous APC originating from SVC. P wave polarity was positive in leads I and II, and morphology of the $\mathrm{P}$ wave in lead II showed a narrow $\mathrm{P}$ wave angle and the absence of a notch. Abbreviations see in Figs 1,3,4.

plotting a ROC sensitivity-specificity curve (the best value was $39^{\circ}$, but the results were the same between $40^{\circ}$ and $39^{\circ}$ ). A P wave angle in lead II of $>40^{\circ}$ yielded a sensitivity of $78 \%$ and a specificity of $92 \%$ for distinguishing SVC origin from RSPV origin. Combined criteria ( $\mathrm{P}$ wave notching $+\mathrm{P}$ wave angle $=>40^{\circ}$ in lead II) yielded a sensitivity of $67 \%$ and a specificity of $100 \%$ for distinguishing SVC origin from RSPV origin (Table 3). Four APC foci were identified in the RSPV, and 3 APC foci were identified in the SVC 
(Table 2). P wave morphology of these APCs showed similar findings for separating SVC origin from RSPV origin (Fig 5).

\section{Discussion}

\section{Major Findings}

Study 1 Selective pacing at each of the $4 \mathrm{PV}$ s produced distinct $\mathrm{P}$ wave characteristics that could be used to identify the pacing site origin in the PV. Left PV pacing produced a low $\mathrm{P}$ wave amplitude (flat or negative $\mathrm{P}$ wave) in lead I and a notched morphology in lead $\mathrm{V}_{1}$. Conversely, the right $\mathrm{PV}$ origin was suggested by a positive $\mathrm{P}$ wave of $\geq 50 \mu \mathrm{V}$ in lead II and unimodal morphology in lead $\mathrm{V}_{1}$. Superior PV origin was suggested by a positive $\mathrm{P}$ wave of $\geq 100 \mu \mathrm{V}$.

Study 2 Differentiation of SVC origin from RSPV origin was possible by a sharp P wave angle $\left(\leq 40^{\circ}\right)$ and the absence of $\mathrm{P}$ wave notching. Thus, the combined use of the $\mathrm{P}$ wave amplitude of lead I, the $\mathrm{P}$ wave amplitude, notching, and angle in lead II, and the $\mathrm{P}$ wave notching in lead $\mathrm{V}_{1}$ is useful for predicting the origin of the APC in the PVs and SVC.

We adopted leads I and II for predicting spontaneous APC foci to simplify the analysis, but our algorithm for differentiating APC origin in the PV and SVC was confirmed with high sensitivity and specificity (70-90\%) despite whether there was obscuration by the prior $\mathrm{T}$ wave.

\section{Previous Studies}

Previous studies showed pacemapping from each of the PVs ( $\mathrm{P}$ wave amplitude in lead I, $\mathrm{P}$ wave duration, amplitude ratio of III/II and sum of the $\mathrm{P}$ wave amplitude in all the inferior leads) and SVC (P wave polarity in leads I and $\mathrm{aV})^{10-14}$ To the best of our knowledge, our study is the first to attempt to correlate the $\mathrm{P}$ wave morphology during pacing in the PVs and SVC with spontaneous atrial ectopic beats of PV and SVC origin.

Tse et al reported $\mathrm{P}$ wave polarity during pacing from the PVs and right atrium!1 They found that the combination of a negative or biphasic $\mathrm{P}$ wave in lead I and positive $\mathrm{P}$ wave in lead $V_{1}$ was highly specific for the origin of the pacing site from the PVs. A positive $\mathrm{P}$ wave in the inferior leads was associated with pacing sites in superior PVs. In their study, $\mathrm{P}$ wave polarity had only limited value in distinguishing pacing sites in left and right PVs! ${ }^{11}$ Yamane et al reported $\mathrm{P}$ wave characteristics during $\mathrm{PV}$ pacing! ${ }^{2}$ Their study showed that the right $\mathrm{PV}$ pacing produced a positive $\mathrm{P}$ wave in lead I, flat $\mathrm{P}$ wave in lead $\mathrm{aV} \mathrm{L}$, and a low lead III/II amplitude ratio. There was a significant difference in the P wave duration between the right and left PVs; however, the ability to distinguish between right and left PV origin was modest. The P wave amplitude in lead II distinguished superior PVs from inferior PVs with a 74\% specificity and a $81 \%$ sensitivity. A notched $\mathrm{P}$ wave in lead II showed a $92 \%$ specificity in predicting left PV origin!2

Kuo et al reported that the combination of biphasic or isoelectric $\mathrm{P}$ wave polarity in lead $\mathrm{V}_{1}$ or biphasic $\mathrm{P}$ wave polarity in lead $\mathrm{aV}$ had moderate sensitivity $(71 \%)$ and specificity (82\%) in predicting an arrhythmogenic focus of AF from the SVC!3 They studied spontaneous atrial ectopic beats only from the SVC and RSPV. Our results showed that presence of notch and $\mathrm{P}$ wave angle in lead II can differentiate the origin of APC from SVC or RSPV by a sensitivity of $78 \%$ and a specificity of $92 \%$. Rajawat et al attempted to correlate the $\mathrm{P}$ wave morphology of spontane- ous atrial ectopic beats with PV origin. Their study yielded the following criteria for distinguishing right-sided from left-sided PV origin: (1) a P wave duration <120 ms; (2) a P wave amplitude in lead I of $>0.05 \mathrm{mV}$; and (3) a P wave amplitude in leads II $/$ III of $>1.25 \mathrm{mV}$. The criterion for distinguishing superior from inferior PVs was the sum of the $\mathrm{P}$ wave amplitudes in all inferior leads $>0.3 \mathrm{mV} !{ }^{14}$

Their study ${ }^{14}$ results document that surface ECG P wave simple morphology criteria in leads I and II can predict LSPV, LIPV, RSPV, RIPV, and SVC arrhythmogenic focus of atrial ectopic beats with good sensitivity and specificity (sensitivity of $83-89 \%$ and specificity of $86-92 \%$ for PVs, and sensitivity of $78 \%$ and specificity of $92 \%$ for SVC), which was similar to previously reported results.

\section{Clinical Implications}

Identification of a specific arrhythmogenic PV can be difficult, particularly in patients with infrequent ectopy during an ablation procedure. This is particularly useful in the youngest patients, who typically have a single arrhythmogenic PV 15 The establishment of surface ECG criteria for identifying the origin of spontaneous atrial ectopy in a PV might facilitate the rapid localization of arrhythmogenic PVs and SVC with a single triggering ectopic beat. The described surface ECG criteria can also be used to localize the arrhythmogenic focus to a PV or the SVC during limited lead monitoring prior to the ablation procedure. These data are of critical importance when spontaneous atrial ectopic beats triggering AF originate only from the SVC. In such cases, transseptal puncture can be avoided. Furthermore, in the absence of frequent spontaneous events that afford the opportunity for more detailed mapping, the presence of confirmed spontaneous events originating from the left and right PVs prior to the procedure allows the physician to anticipate the need to isolate all the PVs and also allow more time to evaluate potential reconnection by isolation of the arrhythmogenic PVs first.

\section{Study Limitations}

$\mathrm{P}$ wave morphology during pacing might be different from spontaneous ectopic atrial premature complexes, particularly at short coupling intervals. In addition, spontaneous APCs that trigger AF are frequently superimposed upon the prior T wave, making analysis difficult. Our algorithm is valid only for pacing from PVs and the SVC at a cycle length of $600-800 \mathrm{~ms}$. The coupling interval of APCs arising within PVs and SVC is usually shorter than the pacing cycle length used in this study, and this might affect the $\mathrm{P}$ wave morphology because of superimposition to the ST-T segment. QRST subtraction might be more helpful in predicting PV and SVC origin of these APCs! ${ }^{16}$

There is a minority of patients with focal atrial AF for which the trigger is not located in any of the PVs or the SVC; the algorithm in this study was not developed to localize such a focal atrial source outside the PVs or SVC.

Another limitation is that all of the patients in this study were free of structural heart disease, persistent AF, and electrical or structural atrial abnormalities, and therefore the results might not apply to patients with structural heart disease or dilated atria. O'Donnell et al ${ }^{17}$ showed that changes in $\mathrm{P}$ wave morphology during decremental pacing were observed in 5\% of controls, but in over $25 \%$ of persistent AF patients. Many more patients had APCs of RSPV and LSPV origin than of RIPV and LIPV origin (Table 1). Consequently, the specificity of a positive $\mathrm{P}$ wave in lead II for 
detecting a superior origin is much less reliable than the sensitivity. We did not compare the $\mathrm{P}$ wave morphology during pacing from different bipoles in the same PV. However, Dixit et al showed that unique intracardiac activation patterns during ostial pacing from individual PVs are not influenced by the circumferential location of the PV pacing site ${ }^{18}$

Although all 4 PV isolation had become the standard strategy of AF-ablation, recently published papers demonstrated that in patients with clearly documented arrhythmogenic PVs, the segmental PVI of the PV triggering the AF or an ipsilateral PV had a comparable long-term success rate and shorter RF energy delivery and procedure times than the empirical 4 PV isolation method 19,20

Finally, we did not perform activation sequence mapping of the left and right atria during 4 PVs and SVC pacing to elucidate why $\mathrm{P}$ wave morphology is different during pacing from 4 PVs and SVC.

Further studies are needed to evaluate the role of specific anatomic structures such as septopulmonary bundle and Bachmann's bundle for intra and inter atrial conduction sequence by using a 3-D mapping system.

\section{Conclusions}

Analysis of the surface ECG can often provide enough information to help localize the PV or the SVC origin of spontaneous APCs despite their superimposition upon the T wave. Surface ECG criteria based on P wave amplitude in lead I and notching in $\mathrm{V}_{1}$ can help distinguish right-sided from left-sided origin of spontaneous APCs, P wave amplitude in lead II can help distinguish superior from inferior PV origin of spontaneous APCs, and P wave angle and notching in lead II can help distinguish RS from SVC origin of spontaneous APCs.

\section{References}

1. Jais P, Haissaguerre M, Shah DC, Chouairi S, Gencel L, Hocini M, et al. A focal source of atrial fibrillation treated by discrete radiofrequency ablation. Circulation 1997; 95: 572-576.

2. Haissaguerre M, Jais P, Shah DC, Takahashi A, Hocini M, Quiniou $\mathrm{G}$, et al. Spontaneous initiation of atrial fibrillation by ectopic beats originating in the pulmonary veins. N Engl J Med 1998; 339: 659666.

3. Jais P, Shah DC, Haissaguerre M, Hocini M, Garrigue S, Clementy J. Atrial fibrillation: Role of arrhythmogenic foci. J Interv Card Electrophysiol 2000; 4(Suppl 1): 29-37.

4. Hwang C, Karagueuzian HS, Chen PS. Idiopathic paroxysmal atrial fibrillation induced by a focal discharge mechanism in the left superior pulmonary vein: Possible roles of the ligament of Marshall. $J$ Cardiovasc Electrophysiol 1999; 5: 636-648.

5. Sueda T, Imai K, Watari M, Orihashi K, Shikita H, Matsuura Y. Pos- sibility of focal activation around the left upper pulmonary vein during chronic atrial fibrillation with mitral valve disease. Ann Thorac Cardiovasc Surg 1999; 5: 116-120.

6. Chen SA, Hsieh MH, Tai CT, Tsai CF, Prakash VS, Yu WC, et al. Initiation of atrial fibrillation by ectopic beats originating from the pulmonary veins: Electrophysiological characteristics, pharmacological responses, and effects of radiofrequency ablation. Circulation 1999; 100: 1879-1886.

7. Chen SA, Tai CT, Yu WC, Chen YJ, Tsai CF, Hsieh MH, et al. Right atrial focal atrial fibrillation: Electrophysiologic characteristics and radiofrequency catheter ablation. J Cardiovasc Electrophysiol 1999; 10: $328-335$.

8. Lin WS, Tai CT, Hsieh MH, Tsai CF, Lin YK, Tsao HM, et al. Catheter ablation of paroxysmal atrial fibrillation initiated by non-pulmonary vein ectopy. Circulation 2003; 107: 3176-3183.

9. Tsai CF, Tai CT, Hsieh MH, Lin WS, Yu WC, Ueng KC, et al. Initiation of atrial fibrillation by ectopic beats originating from the superior vena cava: Electrophysiologic characteristics and results of radiofrequency ablation. Circulation 2000; 102: 67-74.

10. Deen V, Vohra J, Kalman J. Characteristic P wave morphology during pulmonary vein pacing (abstract). Pacing Clin Electrophysiol 1999; 22(Part II): 771.

11. Tse HF, Lau CP, Lee KL, Pelosi F, Oral H, Knight BP, et al. P wave polarity during pacing in pulmonary veins. J Interv Card Electrophysiol 2001; 5: 167-172.

12. Yamane T, Shah D, Peng JT, Jais P, Hocini M, Deisenhofer I, et al. Morphological characteristics of $\mathrm{P}$ waves during selective pulmonary vein pacing. J A Coll Cardiol 2001; 38: 1505-1510.

13. Kuo JY, Tai CT, Tsao HM, Hsieh MH, Tsai CF, Lin WS, et al. P wave polarities of an arrhythmogenic focus in patients with paroxysmal atrial fibrillation originating from superior vena cava or right superior pulmonary vein. J Cardiovasc Electrophysiol 2003; 14: $350-357$.

14. Rajawat YS, Gerstenfeld EP, Patel VV, Dixit S, Callans DJ, Marchlinski FE. ECG criteria for localizing the pulmonary vein origin of spontaneous atrial premature complexes: Validation using intracardiac recordings. Pacing Clin Electrophysiol 2004; 27: 182-188.

15. Haissaguerre M, Jais $P$, Shah DC, Garrigue S, Takahashi A, Lavergne $\mathrm{T}$, et al. Electrophysiological end point for catheter ablation of atrial fibrillation initiated from multiple pulmonary venous foci. Circulation 2000; 101: 1409-1417.

16. Choi KJ, Shah DC, Jais P, Hocini M, Macle L, Scavee C, et al. QRST subtraction combined with a pacemap catalogue for the prediction of ectopy source by surface electrocardiogram in patients with paroxysmal atrial fibrillation. J Am Coll Cardiol 2002; 40: $2013-$ 2021.

17. O'Donell D, Bourke JP, Furniss SS. P wave morphology during spontaneous and paced pulmonary vein activity: Difference between patients with atrial fibrillation and normal controls. J Electrocardiol 2003; 36: 33-40.

18. Dixit S, Gerstenfeld EP, Rho RW, Patel VV, Callans DJ, Marchlinski FE. Change in distant atrial activation patterns during circumferential pacemapping of pulmonic vein ostium: Implications for localizing triggers for atrial fibrillation. J Interv Card Electrophysiol 2003; 8: 187-194.

19. Dixit S, Gerstenfeld EP, Ratcliffe SJ, Cooper JM, Russo AM, Kimmel SE, et al. Single procedure of control of atrial fibrillation: A prospective randomized study. Heart Rhythm 2008; 5: 174-181.

20. Pak HN, Kim JS, Shin SY, Lee HS, Choi JI, Lim HE, et al. Is empirical four pulmonary vein isolation necessary for focally triggered atrial fibrillation? J Cardiovasc Electrophysiol 2008; 19: 473-479. 